\title{
Ensuring sustainability of the city transportation system: problems and solutions (ICSC)
}

\author{
Irina Makarova ${ }^{1}$, Rifat Khabibullin $^{1}$, Ksenia Shubenkova ${ }^{1 \mathrm{a}}$, and Aleksey Boyko ${ }^{1}$ \\ 1“Service of Transport Systems” Department, Kazan federal university, 423810, Naberezhnye \\ Chelny, Russia
}

\begin{abstract}
Ways to increase sustainability of the city transportation system and, particularly, measures to promote safe public transport and nonmotorized means of transport are considered in the article. Analysis of the existing positive experience shows that complex decisions for a sustainable development of the city transportation system are necessary. Technical and organizational ways to increase the transportation system's sustainability and safety are studied. The results of solution of separate tasks, aimed at completing the goal, are presented: defining transport preferences of the citizens of Naberezhnye Chelny, perspective model of bus route network, a model of an adaptive smart-bicycle. It is shown that the proposed solutions for strategic and operational management will help to enhance efficiency and safety of transportation system.
\end{abstract}

\section{Introduction}

During the debates about sustainable development the participants of the United Nations Conference on sustainable development (Conference "Rio+20" [1]) noted that transportation and mobility are central to sustainable development as means to improve social equity, health, resilience of cities, urban-rural linkages and productivity of rural areas. They recognized the need to promote an integrated approach to policymaking at the national, regional and local levels for transport services and systems to promote sustainable development. Sustainable transport systems development is one of the Global Goals for Sustainable Development [2] and is the priority area of work of the Pan-European Program on Transport, Environment and Health (the PEP). In the Paris Declaration in addition to the four priority goals of the PEP the new priority goal was adopted. This goal is to integrate transport, health and environmental objectives into urban and spatial planning policies by developing capacities and frameworks for integrated urban and spatial planning in order to reduce the impact of transport on health, the environment and land use, increase energy efficiency and support green and healthy mobility and transport as well as sustainable livelihoods [3]. According to the Global Status Report on Road Safety 2015 [4], moving towards more sustainable modes of transport (such as cycling and public transport) has positive effects if associated road safety impacts have been well managed.

${ }^{a}$ Corresponding author: ksenia.shubenkova@gmail.com 
These include increased physical activity, reduced emissions and noise levels, reduced congestion and more pleasant cities.

In Russia, the safety of transport systems is the issue of the day, because number of highway fatalities up 10 thousand vehicles is higher by $10-15$ times, and up 100 thousand people is $2-4$ times higher than in other countries where motorization rate is higher and the network capacity is the same [5]. The reasons for the increasing number of road accidents lie not only in developmental lag of transport infrastructure, but also have organizational nature. Thus, Moscow roads have been designed for a 4 million vehicles maximum, while the number of registered vehicles today is about 4.5 million. This is the reason of the fact that the average vehicle speed today is $7 \div 11 \mathrm{~km} / \mathrm{h}$ and the drivers have to spend a lot of time in traffic jams. Even the day-time lorry traffic ban in the city center could not significantly improve the situation [6]. Another problem faced by an ordinary vehicle driver is the lack of parking space in the city center. In other major Russian cities, the situation is not much better, and even youngish cities where are wide avenues are familiar with the problem of traffic jams and lack of parking space.

\section{Ensuring sustainability of the city transportation system}

\subsection{Ways to increase sustainability of the city transportation system}

Sustainability of the city transport system is usually means the effective organization that is characterized by the following: a) transport infrastructure provides safe and comfortable travel to all road users: to the drivers of private vehicles, to the passengers of public transport, to cyclists and pedestrians, regardless of their physical disabilities; b) public transport provides affordable (financially and physically) services to all citizens and it is an acceptable alternative to private vehicles when their using leads to overloading of the road network; c) the way of traffic organization ensures the most efficient use of the existing road network, reduction of traffic jams and negative transport-related impact on the environment [7]. One of the most important factors that confirm the effectiveness of the organization of the transport system is existence of strategic planning. Methods to ensure sustainability that are developed within the framework of strategic planning are based on finding a balance between transport demand and supply of the most effective and safe modes of transport (Figure 1).

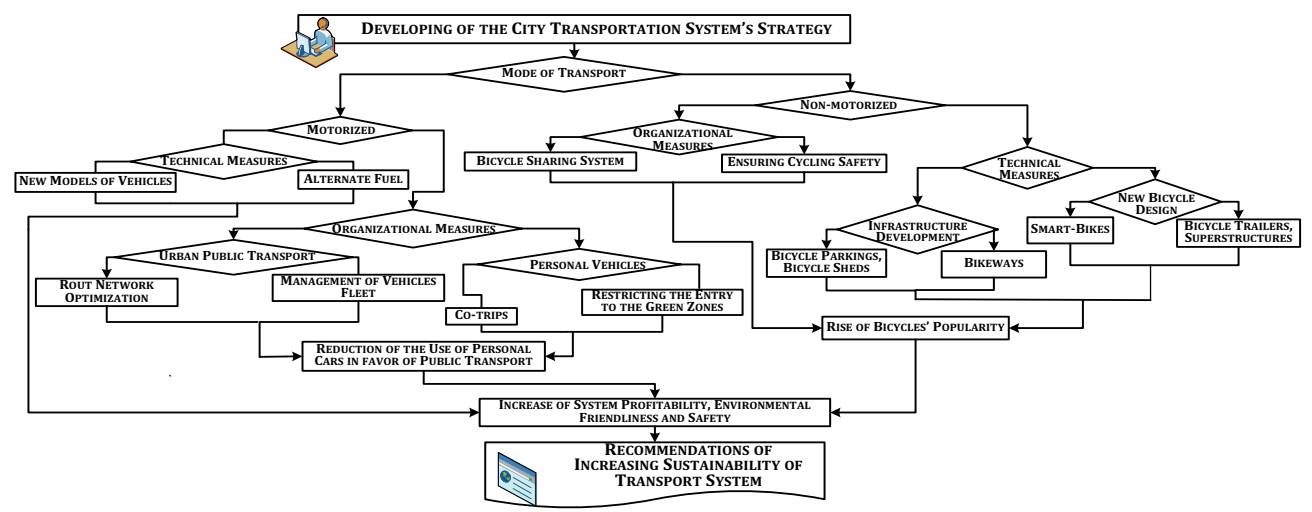

Fig. 1. Methods of increasing sustainability of the city transportation system.

Moving towards more sustainable modes of transport has positive effects if the associated road safety impacts have been well managed. Aside from reducing road 
traffic injuries, there are positive health benefits that are associated with increased physical activity, reduced pollution, noise levels and greenhouse gas emissions, reduced congestion and more pleasant cities. Moreover, measures to promote safe public transport and nonmotorized means of transport are also in line with other global moves to fight obesity and reduce noncommunicable diseases (such as heart disease, diabetes) [8].

\subsection{Positive examples of increasing sustainability of the city transportation system}

In the documents of the PEP it is noted that there are inspiring examples of improving the quality of the urban environment and supporting a modal shift towards cycling and walking in combination with public transport. These positive changes include the investments of cities such as Paris and Barcelona in cycling infrastructure and city bikes, the introduction of congestion charges in London, Stockholm and other cities and interventions made in New York to "pedestrianize" highly congested areas and turn them into parks [9]. It is also noted that electric mobility is becoming more affordable and widespread. Many corporate vehicle fleets and vehicle-sharing schemes across the pan-European region rely on electric and/or hybrid vehicles and the introduction of electric bicycles has made it possible to use cycling not only for health and leisure, but as a viable means of transport. Among the factors constraining the development of alternative ways of movement is the fact that only 68 countries have national or subnational policies to promote walking and cycling, and just 79 countries have policies that protect pedestrians and cyclists by separating them from motorized and high-speed traffic [10].

In Germany as part of the «50 by 50» campaign [11] some communities have started moving towards the «carfree city», for example, one such community is Vauban (Germany). This approach is ensured by high-quality public transport, walking and cycling facilities, as well as limited and costly parking [8]. The government of the neighbor city Freiburg in order to achieve objectives of transport-related environmental pollution abatement is constantly investing in the non-motorized transport development. Last years about 6000 bicycle parkings (including tandems and bicycles with a trailer) have been built there. The main purpose of this action is to make bicycles popular not only among students but also among businessmen, women and children. In order to incorporate cycling into a united city transportation system bicycle parkings have been built also at several selected bus stops of the public transport [12].

The bicycle sharing system was implemented in the Republic of Korea in the city of Changwon, where old technology (the bicycle) has been matched up with the new technology (smartcards), so that bikes can be used on demand, either free for an initial period or for a reasonable charge. Bicycle sharing system is also implemented in Hangzhou (China), where the popularity of this mode of transport is also provided by the widespread introduction of electric bicycles [8]. Today, road users of many European cities (such as Oulu, Amsterdam or Copenhagen) at two-thirds consist of cyclists. However, not everyone can ride a bicycle every day, especially long-distance cycling. That is why bicycles should be considered not as a competitor, but rather as an addition to other modes of transport. Thus, the use of personal cars for daily trips may be reduced providing: the right transport links between all parts of the are established by public transport; sufficient reasons for not owning a vehicle (e.g. limited and costly parking); local walking and cycling facilities and services.

In most cases of successful implementation, however, it is not a single policy that has been introduced - but rather a package of measures. Such 'packages' are more likely to gain public acceptance, and they allow a mixture of policies that may be seen as disadvantageous to individual users, but promote overall welfare gains to society [8]. 


\subsection{Improving the quality of public transport governance}

The shift from personal cars to public transport without sacrificing mobility of the population can be ensured by increasing the safety and comfort of its services [13] that is considerably has a direct link with improving the quality of public transport governance. The operational management of large systems, which also include transportation system, decision support systems (DSS) are used. Intelligent hearts of such systems can be various means that provide analysis of the operational information about system parameters, such as: parameters of traffic flow, road accidents and other emergency situations. Such systems may include sets of canned solutions for different factor combinations that facilitate, if necessary, a reasonable selection of the best managerial solution.

These decisions can be laid at the strategic planning stage. The management quality indicators are increasing of safety, reliability and sustainability of the system. The correctness of such a system's operation is largely determined by the quality of the initial information and the adequacy of its analyzing and processing methods. For analysis and development of recommendations in the DSS information search, data mining, knowledge retrieval in databases, reasoning based on precedents, simulation modeling, evolutionary computation and genetic algorithms, neural networks, situational analysis, cognitive modeling, etc are used. There are three main parts in the DSS: 1) Data system for collection and storage of information received from internal and external sources, as a rule, it is a data store; 2) the system of dialogue that allows the user to specify what data to choose and how to handle them; 3 ) the system of models - ideas, algorithms and procedures that allow to process data and to analyze them. The user has the experience, knows the situation and follows certain considerations when fetching data. In the processing of data, use different procedures, from simple summing to statistical analysis and nonlinear optimization.

The intellectual heart of the designed system is a transport model, which is a software package, consisting of a Network Model, Travel Demand Model and Impact Model. The Network Model is a representation of the road network and in that way means a city transport supply. The Travel Demand Model contains the travel demand data (cost matrix, origin-destination matrices, etc.), and describes the transport needs of the population with a standard four-stage model usage. Impact Models allow to evaluate comprehensively each option of the traffic organization and to choose the best from the point of view of increasing the efficiency of use of the vehicle fleet of transport enterprises, and with a view of minimizing the negative impact on the environment without compromising it's mobility [14].

Origin-destination matrices creating and the traffic flows distribution allows using Network Model and Travel Demand Model that take into account parameters of the real system. It is necessary to have qualitative operational information on these current system parameters values for the correct model simulation. Realization of the concept of "Safe City" (in Russian cities) contributes to improving the quality of information through the paragraph "Transport Security" [15] where the objectives for road safety are formulated. Thus, in Naberezhnye Chelny to the end of 20161020 video cameras will be installed on dwellings, social and cultural objects and transport infrastructure objects (roadways, public transport stops and passenger compartments, etc.). This will allow collecting operational information and adjust the operational management based on data analysis.

Simulation models designed just as for the whole city, so for the areas with critical values of traffic parameters, enable to choose the best options for different values of the initial parameters. As a result of the simulation traffic loads are calculated that helps to identify problem areas that should be optimized. After the model verification and validation it can be used to correct city route network in order to avoid buses passing 
through the overloaded road network areas. After the route network correction it is the structure of the vehicle fleet on the bus routes that is optimized according to their operating characteristics. And then the traffic schedule is formed, taking into account the maximum allowable traffic intervals. Economic effect of DSS application is determined by the reduction of transportation costs by optimizing routes and increasing efficiency of the vehicle fleet. Environmental effect is to reduce the negative impact on the environment and can be achieved through rational redistribution of traffic flows on the city road network. Social effect will be the reduction of the risk of disease due to urban air quality as well as in decreasing delays and the fatigue of the population in the process of reaching destinations.

\subsection{Development of a sustainable system of non-motorized transport}

Bicycling makes efficient use of roadway capacity and reduces congestion. It is a lowpolluting and a low-cost transportation alternative and can be an important means for getting to destinations that are not serviced by transit [16]. The advantages of cycling include cheap infrastructure requirements and improvements in public health. Bicycle pathways, lanes and parking require less space than their automobile counterparts. Cycling has direct health benefits. It is an aerobic exercise that can minimize the risk of muscle and ligament injury, lower blood pressure and reduce the risk of heart disease) [17]. Moreover, in urban areas, cycling can sometimes prove to be faster than other transport modes and also allows cyclists to avoid traffic jams. But at the same time cycling has a number of disadvantages, however, including a greater physical effort, the difficulty of carrying loads while cycling, being at the mercy of the weather, and, outside urban areas, travelling more slowly than motorized transport. Factors such as physical effort and speed also limit the distance that a cyclist can travel [18]. These activities may promote cycling: the design of cycle paths, taking into account such factors as the terrain; the elaboration of new bicycle designs, such as smart-bike, electric bike, cargo bike, bike for passengers transportatio (children, the disabled people, the old people), etc.; integration of bicycles to public transport infrastructure (bike parkings at public transport stops, the possibility to take the bike in buses or trams); development of cycling infrastructure: safe bike paths with rain, wind and sun protection, secure bicycle parkings at all destinations, bicycle sharing system, etc.

The attractiveness of cycling may be increased by the expansion of the model line-up of bicycles for different population groups and various use cases. One of the solutions could be a smart bike usage. Currently electric bicycles have found wide application. They are generally different from ordinary bicycle because of three additional components presence such as an electric motor, a storage battery and a battery controller. In contrast to the electric scooter or motorcycle, electric bike may be driven by pedals and it's operation and maintenance is a little more complicated than an ordinary bicycle handling. Despite of electric drive presence electric bike is used approximately the same as an ordinary bicycle and in most countries does not require the driving license or license plate presence. Electric bicycle is suitable as a vehicle for a wide range of people with the different level of abilities, as it is easy to dose physical training. There is a number of disadvantages of electric bicycle that, makes it difficult to use. They are: significant weight (from 20 to $50 \mathrm{~kg}$ or more) and the corresponding inertia; lack of power reserve on the drive (rarely more than 25-50 km); long battery charging (usually at least 2-6 hours); short service life of lead-acid and lithium-Ion storage batteries; the high cost of the final product and its use compared with an ordinary bicycle cost and use (from 2 to 10 times). 


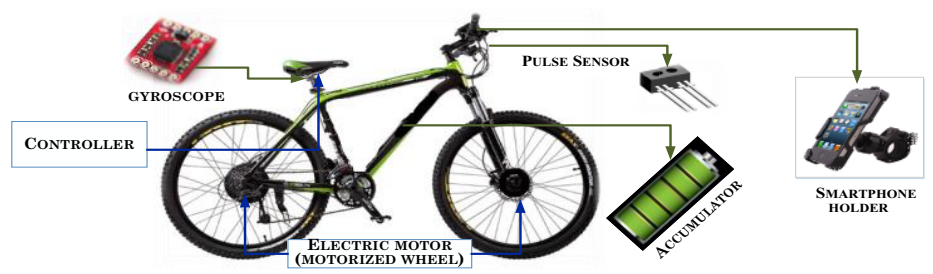

Fig. 2. The elements that are included in the developed module.

Electric bicycles are controlled by bicycle computer (controller), which is supposed to: supply amperage from the battery to the electric motor in accordance with the user's settings; show residual battery charge on the indicator; determine the rotation / stop of pedals; limit the maximum speed of the bicycle movement in order to save energy;keep constant speed (cruise control); charge the battery while braking. At the same time there is a variety of stationary bicycles that are belong to the group of cardiovascular machines which are equipped to control the physical condition of a user. At the same time the main indicator to diagnose critical state is a pulse rate. If to equip the bicycle with the universal module, which includes a pulse sensor, a controller and other components that are shown in Figure 2, and to manage it in accordance with the selected program installed on smartphone it will help to increase the attractiveness of cycling among untrained population. Application of the developed module will enhance the attractiveness of the bicycle due to the fact that owners of such vehicles may have insufficient training and at the same time the overload risk will reduce.

\section{Application of imitation models to choose the best way of increasing sustainability of the city transportation system}

Addressing the issues of urban mobility ensuring that is directly related to the city transportation sustainability should be based on and taking into account the preferences of the population. Only in this case the projects will be successful, and it ensures the effectiveness of investments to transport system infrastructure. To justify the choice of the best options there are two important aspects in strategic planning. They are the adequacy and quality of the initial information on the current state of the transport system as well as the preferences of the population that is necessary for predictive models design. The best tool for the comparison of options is a simulation. One of the most objective methods to study the transport preferences of the population is a questionnaire survey, that allows to predict the most likely options of the transportation system development. These surveys should be carried out in proper structuring and data processing and also with an allowance for risks.

To find out what transport modes population of Naberezhnye Chelny prefer and what are the transport problems from the consumers' point of view the questionnaire has been developed. 953 respondents, constituting the various target groups, took part in the current survey (Table 1). To analyse possible directions of Naberezhnye Chelny transportation system's development a comparison of transport mobility indicators of its population and the population of Kopengagen, that is similar in size [19], was made (Table 2).

Table 1. The results of the sampling survey of population of Naberezhnye Chelny.

\begin{tabular}{|c|c|c|c|c|c|}
\hline Indicator & 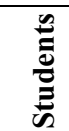 & 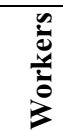 & 苞 & 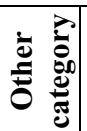 & 岕 \\
\hline number of respondents & 624 & 299 & 16 & 14 & 953 \\
\hline
\end{tabular}




\begin{tabular}{|c|c|c|c|c|c|}
\hline number of trips to work or education by public transport & 313 & 109 & - & - & 422 \\
\hline number of trips to work or education by bicycles & 50 & 7 & - & - & 57 \\
\hline number of trips to work or education by cars & 163 & 133 & - & - & 296 \\
\hline number of trips to work or education by foot & 98 & 50 & - & - & 148 \\
\hline \multicolumn{6}{|c|}{ the number of drivers who are ready to transfer to bicycles, if there are: } \\
\hline • $\quad$ bikeways & 127 & 56 & 0 & 0 & 183 \\
\hline - $\quad$ bicycles parkings & 129 & 46 & 0 & 0 & 175 \\
\hline - $\quad$ bike hire system & 75 & 28 & 0 & 0 & 103 \\
\hline $\begin{array}{l}\text { - the possibility to take the bike in buses or } \\
\text { trams }\end{array}$ & 76 & 21 & 0 & 0 & 97 \\
\hline - $\quad$ E-bikes & 78 & 22 & 0 & 0 & 100 \\
\hline \multicolumn{6}{|c|}{ the number of drivers who are ready to transfer to public transport, if there are: } \\
\hline $\begin{array}{l}-\quad \text { busstops can be reached by foot in less than } \\
5 \text { minutes }\end{array}$ & 85 & 38 & 1 & 0 & 123 \\
\hline - $\quad$ bus waiting time is 5 minutes or less & 89 & 47 & 1 & 1 & 136 \\
\hline direct connection, no transfers & 73 & 45 & 1 & 1 & 118 \\
\hline vehicles are clean and comfortable & 94 & 40 & 1 & 0 & 134 \\
\hline place to sit & 78 & 37 & 1 & 0 & 116 \\
\hline \multicolumn{6}{|l|}{ travel modes preferences: } \\
\hline \multirow{3}{*}{$\begin{array}{ll}- & \text { buses } \\
- & \text { minibuses } \\
- & \text { trams } \\
\end{array}$} & 127 & 88 & 6 & 6 & 227 \\
\hline & 371 & 115 & 3 & 6 & 495 \\
\hline & 134 & 59 & 7 & 1 & 201 \\
\hline number of bikes in the personal property & 313 & 86 & 2 & 6 & 407 \\
\hline
\end{tabular}

Priority strategy of politicians in Copenhagen is development of bicycles infrastructure as a way to create more friendly city living condition. The conditions for the implementation of a "green transport" strategy are also created in Tatarstan as well as in a number of Russian cities. Moving towards more sustainable modes of transport (for example, gas and hybrid buses, popularization of cycling) is realizing in order to support this strategy. Any changes in the city transport infrastructure should take into account a great amount of factors, as well as the preferences of the population of the city. The results of the survey conducted in Naberezhnye Chelny have shown that reducing the number of trips by vehicle in favor of the public transport can be achieved by route network improving, as well as the optimization of structure of the vehicle fleet on the bus routes.

Table 2. The comparison of transport mobility indicators.

\begin{tabular}{|l|c|c|}
\hline \multicolumn{1}{|c|}{ Indicator } & Kopengagen & Naberezhnye Chelny \\
\hline number of inhabitants & 550000 & 522000 \\
\hline city area, km ${ }^{2}$ & 88,25 & 171,03 \\
\hline number of vehicles in the personal property & 125 & 147 \\
\hline number of bikes in the personal property & 650000 & $\mathrm{n} / \mathrm{a}$ \\
\hline number of cars per capita & 0,23 & 0,28 \\
\hline average number of bikes per capita & 1,2 & 0,43 \\
\hline bikeways length, km & 350 & 110 \\
\hline bikeways length per square of the city, KM/KM ${ }^{2}$ & 3,96 & 0,64 \\
\hline trips to work or education by public transport, \% & 32 & 44 \\
\hline trips to work or education by bicycles, \% & 36 & 6 \\
\hline trips to work or education by personal vehicles, \% & 26 & 31 \\
\hline motorized and non-motorized transport integration: & & \\
\hline - the possibility to take the bike in buses or trams & + & - \\
\hline - bike parkings at public transport stops & + & - \\
\hline secure bicycle parkings at all destinations & + & - \\
\hline public transport operates day and night & + & - \\
\hline
\end{tabular}




\begin{tabular}{|l|l|l|}
\hline availability of shortened bus routes & + & - \\
\hline availability of high speed bus routes & + & - \\
\hline the presence of additional routes during peak hours & + & - \\
\hline
\end{tabular}

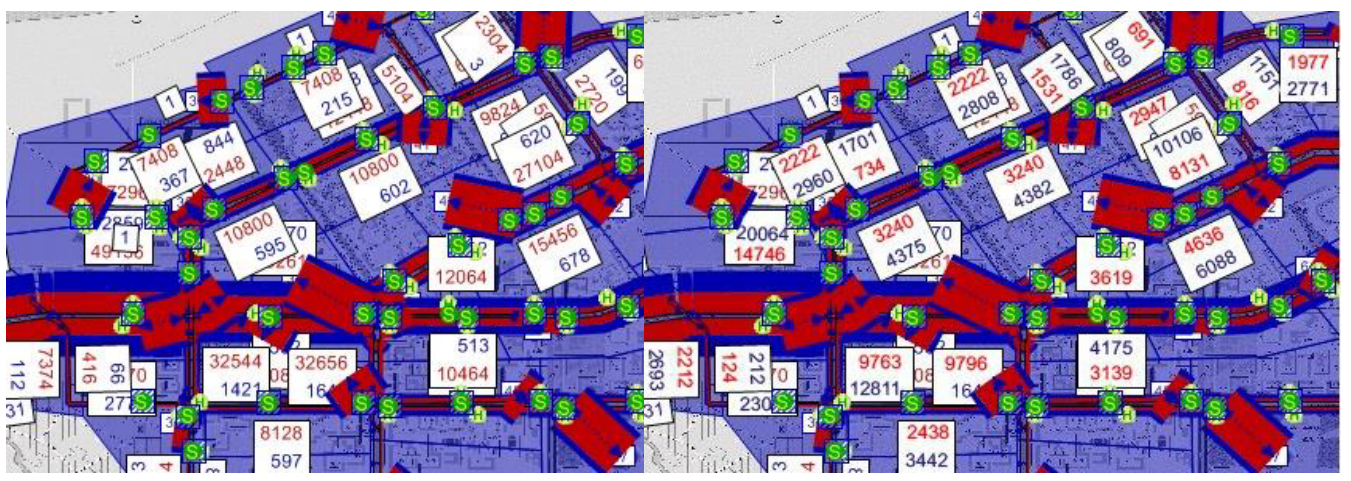

a)

b)

Fig. 3. The traffic load distribution: a) existing passenger flow and route network; b) predicted passenger flow.

Firstly, predictive model of the new route network has been developed taking into account the following conditions: a) route network optimization should be carried out in such a way that, on the one hand, to eliminate (as far as possible) the imposition of routes, and on the other, to link all traffic areas of the city through direct routes; b) according to respondents, about $70 \%$ of drivers are willing to stop using private cars in favor of more sustainable modes of transport. That's why changes of modified trip distribution coefficients were introduced into the Travel Demand Model and the predicted values of traffic loads on the road network areas were calculated; c) while the vehicle fleet structure and the bus schedule optimization the predictive number of passengers should be taken into account. What's more it should be adjusted by changing traffic parameters. The suggested variants checking should be carried out with the help of simulation models. There is the road network area before and after the suggested changes in the Figure $3(a, b)$. The red marks number of personal cars on the area, and blue marks the number of public transport passengers. Data on public transport demand allow to calculate the optimal number of different types of vehicles for each route. Thus, increasing the attractiveness of the public and non-motorized modes of transport will make the traffic load almost two times lower, and improve the ecological situation in the city.

\section{Conclusion}

Sustainable urban mobility requires high-performance public transport system and a combination of different modes of transportation. At the same time it has significant potential for the cycling development, because this clean and efficient kind of transportation contributes not only to the increasing of the city transportation system sustainability, but also to the economy's development. The experience of developed countries shows that in England bicycle accessories selling brings $£ 853$ mill. per year, 23,000 people employed in the cycling industry get $£ 500$ mill. per year and respectively pay $£ 100$ mill. of taxes. There are a lot of obstacles to the widespread use of the bicycles as an alternative travel mode in Russia. However, the development of an adaptive E-bike, bicycles infrastructure and it's integration to the public transport system will contribute to use of bicycle and public transport. City transportation system is a complex multi-parameter 
system, that's why every potential change in the traffic and passenger flows structure should be assessed comprehensively using DSS. The developed control system allows not only to analyze "what if...", but also evaluate each variant of arranging public transport's traffic and to choose the best both in terms of more efficient use of the vehicle fleet of transport enterprises and with a view to minimizing the negative impact on the environment while maintaining the mobility of the population. Thus, moving towards sustainable transport in Russian cities is possible today and depends on depends on the presence of supportive and nurturing governance, as well as sound institutional and regulatory structures.

\section{References}

1. The future we want. Rio de Janeiro: United Nations (2012)

2. Global status report on road safety 2015 (WHO Library Cataloguing-in-Publication Data, 2015)

3. Paris Declaration. City in motion: People first (Geneva: United Nations Publications, 2015)

4. E.B. Barbier, A global green new deal: Rethinking the Economic Recovery (Cambridge: Cambridge University Press 2010)

5. M.V.Zelencov, Improving city traffic safety based on neural networks and discriminant analysis techniques (Orel, 2010)

6. Changing urban traffic and the role of bicycles: Russian and International Experiences (Friedrich-Ebert-Stiftung, 2014)

7. The national concept of sustainable city transportation systems (2013)

8. Global Report on Human Settlements (UN-HABITAT, 2013)

9. Preparation of the Fourth High-level Meeting on Transport, Health and Environment (United Nations Publications, 2014)

10. Global status report on road safety 2013: supporting a decade of action (Geneva: WHO Library Cataloguing-in-Publication Data, 2013)

11. Share the Road Programme (UNEP, 2015)

12. A.V. Finogenov, Urban development, Vision Expo: Report (2010)

13. Green and healthy jobs in transport: launching a new Partnership under THE PEP (2011)

14. I.V. Makarova, R.G. Khabibullin, K.A. Shubenkova, World transport and technological machinery, 50, 103-114 (2015)

15. The order of the Russian Federation "The Concept of developing the hardware and software complex "Safe City". Available at: www.rg.ru/2014/12/11/gorod-sitedok.html

16. S. Handy, Y. Xing, International Journal of Sustainable Transportation, 5, 91-110 (2011)

17. S. Tsenkova, D. Mahalek, Urban, Planning and Transport Research, 2, 126-146 (2014)

18. E. Heinen, B. van Wee, K. Maat, Transport Reviews, 30, 59-96 (2010)

19. Lonely planet: Denmark. Available at: http://www.lonelyplanet.com/denmark/copenhagen 